\title{
Not everything that jerks is epilepsy
}

Many sporting activities are associated with risk and with injury. The occurrence of apparently convulsive episodes in response to injury is dramatic but often misinterpreted, to the detriment of those sportsmen and sportswomen who have suffered them. The benign nature of these episodes and their non-epileptic basis needs to be recognised in sports medicine.

\section{Syncopal convulsions}

Classical medical teaching is that syncope results in atonic collapse with motionless unconsciousness for a brief period of time. For many years Stephenson has emphasised that this is far from the truth, ${ }^{1}$ and the frequency with which convulsive movements and automatisms can occur during syncope has recently been emphasised by Lempert and colleagues. ${ }^{2}$ They studied a series of German medical students in whom fainting was induced by the "mess trick" or "fainting lark". ${ }^{3}$ They were asked to squat and hyperventilate for 30-45 seconds, after which they stood erect and performed a Valsalva manoeuvre. This resulted in syncope and collapse in 49 out of 52 subjects, and of those collapsing, $90 \%$ exhibited a variety of myoclonic movements, which were occasionally focal but more commonly multifocal or generalised. This could last up to 16 seconds, but lasted on average for seven seconds.

Injuries in young people are commonly associated with vaso-vagal syncope where there is a reflex response to pain or to psychogenic factors. The occurrence of convulsive movements with such clearly provoked syncope is entirely benign, and it is well documented that no epileptic activity is seen in the EEG, only a general slowing of activity leading up to and during the period of unconsciousness and myoclonus. ${ }^{4-6}$ The myoclonic activity probably results from a cortical release of the medullary reticular formation. Syncopal convulsions probably represent the single most common cause of a misdiagnosis of epilepsy, which is easily avoidable once a satisfactory history is taken. Syncopal convulsions differ from epileptic convulsions (tonic-clonic seizures) in that they are much briefer and are not associated with significant post-ictal amnesia or longlasting confusion. They can, however, be associated with incontinence and with biting of the tip of the tongue.

\section{Concussive convulsions}

Concussive convulsions occur within seconds of impact and are dramatic events, usually occurring in public view, and receiving heroic attention from first aiders. They are likely to be the cause of media reports, which are attributed to the anatomically unlikely event of the individual "swallowing their tongue". Although these events have been widely assumed to represent a form of post-traumatic epileptic seizure, there is now considerable evidence to the contrary. Careful follow up of subjects with such events by Jennet ${ }^{7}$ indicated that immediate convulsions were not a predictor of late post-traumatic epilepsy, in contradistinction to other seizures occurring in the first post-traumatic week, and that on the whole they tended to be associated with relatively mild concussive head injury. These points have recently been emphasised by McCrory et al. ${ }^{8}$ This Australian group identified 22 concussive convulsions in Australian rules footballers and rugby league players. Convulsions began within two seconds of the head injury and usually consisted of a brief tonic phase followed by bilateral myoclonic jerks. Some versive head movements and asymmetric posturing were seen in some individuals. No convulsions lasted for more than 150 seconds and none of the players had any behavioural or neuropsychological features that suggested anything other than a mild concussion. Performance records were available for follow up for all the Australian rules cases and all had computed tomography or magnetic resonance imaging which was normal. No long term neuropsychological impairments were noted, none had further concussive convulsions (even though they had further sporting head injuries), and none went on to develop epilepsy in a mean follow up of 3.5 years. It is evident that these convulsions can be associated with rapid recovery. The authors refer to a rugby league player in an international match who sustained a concussive convulsion in the opening minute of the game. After recovery he returned to the field to win the man of the match award.

The mechanism for these convulsions is clearly different from that of syncopal convulsions. They occur too quickly to be in any way attributed to cerebral hypoperfusion. No ictal EEG recordings are available, for obvious reasons, but the likelihood is that they again represent cortical release with continued brain stem activity.

The potential misinterpretation of these events is underlined by the experience of a young jockey, Alan Munro, ${ }^{9}$ who undoubtedly experienced two concussive convulsions six years apart in 1990 and 1996. After the second, his jockey's licence was withdrawn for a year on the grounds that it should be treated in the same fashion as a driver's licence!

Doctors in general need to be aware of the frequency of brief, positive, motor activity associated with loss of consciousness due to fainting and concussion. Unfortunately, these phenomena are not widely recognised even among the neurological community, a fact that often leads to inappropriate restriction in drivers. The phenomena are, however, also relevant to doctors judging the fitness of individuals to participate in contact sports and horse riding. Emotive and "knee jerk" reactions to these convulsive episodes must be avoided for the benefit of sportsmen and sportswomen.

DAVID CHADWICK Professor of Neurology

Department of Neurological Science

The Walton Centre for Neurology $\mathcal{E}$ Neurosurgery

Liverpool L9 $1 A E$

1 Stephenson JBP. Fits and faints. Oxford: MacKeith Press, Blackwell, 1990:41-112.

2 Lempert T, Bauer M, Schmidt D. Syncope: a videometric analysis of 56 episodes of transient cerebral hypoxia. Ann Neurol 1994;36:233-7.

3 Howard P, Leathart GL, Dornhorst AC, Sharpey-Schafer EP. The "mess trick" and the "fainting lark". BMF 1951;ii:382-4.

4 Gastaut H, Fischer-Williams M. Electro-encephalographic study of syncope. Its differentiation from epilepsy. Lancet 1957;ii:1018-25.

5 De Maria AA, Westmoreland BF, Sharbrough FW. EEG in cough syncope. Neurology 1984;34:371-4.

6 Aminoff MJ, Scheinman MM, Griffin JC, Herre JM. Electrocerebral accompaniments of syncope associated with malignant ventricular arrhythmias. Ann Intern Med 1988;108:791-6.

7 Jennet B. Epilepsy after non missile head injuries. 2nd ed. London: Heineman,

8 McCrory PR, Bladin PF, Berkovic SF. Retrospective study of concussive convulsions in elite Australian rules and rugby league footballers: phenomenology, aetiology, and outcome. BMF 1997;314:171-4

9 Chadwick D. Wrong diagnosis may deprive people of their livelihood. BMF 1997;314:1283. 